AperTO - Archivio Istituzionale Open Access dell'Università di Torino

\title{
Catestatin Reduces Myocardial Ischaemia/Reperfusion Injury: Involvement of PI3K/Akt, PKCs, Mitochondrial KATP Channels and ROS Signalling.
}

\section{This is the author's manuscript}

Original Citation:

\section{Availability:}

This version is available http://hdl.handle.net/2318/127918

since

Published version:

DOI:10.1007/s00424-013-1217-0

Terms of use:

Open Access

Anyone can freely access the full text of works made available as "Open Access". Works made available under a Creative Commons license can be used according to the terms and conditions of said license. Use of all other works requires consent of the right holder (author or publisher) if not exempted from copyright protection by the applicable law. 


\section{(1) St \\ UNIVERSITÀ DEGLI STUDI DI TORINO}

The final publication is available at Springer via http://dx.doi.org/10.1007/s00424-013-1217-0

Perrelli MG, Tullio F, Angotti C, Cerra MC, Angelone T, Tota B, Alloatti G, Penna C, Pagliaro P. Catestatin reduces myocardial ischaemia/reperfusion injury: involvement of PI3K/Akt, PKCs, mitochondrial KATP channels and ROS signalling. Pflugers Arch. 2013 Jul;465(7):1031-40. 
Catestatin Reduces Myocardial Ischaemia/Reperfusion Injury:

Involvement of PI3K/Akt, PKCs, Mitochondrial $K_{\mathrm{ATP}}$ Channels and ROS Signalling

\author{
Maria-Giulia Perrelli $^{* 1,5}$, Francesca Tullio ${ }^{* 1,5}$, Carmelina Angotti ${ }^{1}$, Maria Carmela \\ Cerra $^{3,4,5}$, Tommaso Angelone ${ }^{3,5}$, Bruno Tota ${ }^{3,5}$, Giuseppe Alloatti ${ }^{2,5}$, Claudia \\ Penna $^{\# 1,5}$, Pasquale Pagliaro ${ }^{\# 1,5}$ \\ ${ }^{1}$ Department of Clinical and Biological Sciences and ${ }^{2}$ Department of Life Sciences and Systems Biology, \\ University of Turin, Italy; ${ }^{3}$ Department of Cell Biology and ${ }^{4}$ Department of Pharmaco-Biology, University \\ of Calabria, Arcavacata di Rende, Italy; ${ }^{5}$ National Institute of Cardiovascular Research, Bologna Italy.
}

* These two authors contributed equally to this work

Short title: Cardioprotection by Catestatin

\author{
\#Address for the correspondence: \\ Claudia Penna \\ PasqualePagliaro \\ Dipartimento di Scienze Cliniche e Biologiche \\ Facoltà di Medicina e Chirurgia "S. Luigi Gonzaga" \\ Regione Gonzole 10 \\ 10043 Orbassano (TO), Italy. \\ Phone: +39011670.5450 \\ Fax: +390119038639 \\ e-mail: claudia.penna@unito.it; pasquale.pagliaro@unito.it
}




\begin{abstract}
Aims: Catestatin (CST) limits myocardial ischaemia/reperfusion (I/R) injury with unknown mechanisms. Clearly phosphoinositide-3-kinase (PI3K), protein-kinase-C (PKC) isoforms, including intra-mitochondrial PKCE, mitochondrial- $K_{A T P}\left(\right.$ mitoK $\left._{A T P}\right)$ channels and subsequent reactiveoxygen-species (ROS)-signalling play important roles in postconditioning cardioprotection, preventing mitochondrial permeability transition pore (MPTP) opening. Therefore, we studied the role of these extra- and intra-mitochondrial factors in CST-induced protection. Methods and Results: Isolated rat hearts and $\mathrm{H} 9 \mathrm{c} 2$ cells underwent I/R and oxidative stress, respectively. In isolated hearts CST (75nM, CST-Post) given in early-reperfusion significantly reduced infarct-size, limited post-ischaemic contracture, and improved recovery of developed left ventricular pressure. PI3K inhibitor, LY-294002 (LY), large spectrum PKC inhibitor, Chelerythrine (CHE), specific PKCE

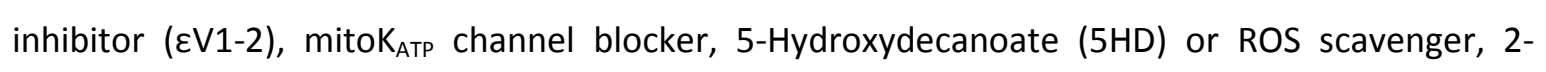
mercaptopropionylglycine (MPG) abolished the infarct-sparing effect of CST. Notably the CSTinduced contracture limitation was maintained during co-infusion of 5HD, MPG or $\varepsilon V 1-2$, but it was lost during co-infusion of LY or CHE. In $\mathrm{H} 9 \mathrm{c2}$ cells challenged with $\mathrm{H}_{2} \mathrm{O}_{2}$, mitochondrialdepolarization (an index of MPTP-opening studied with JC1-probe) was drastically limited by CST (75nM). Conclusions: Our results suggest that the protective signalling pathway activated by CST includes mitoK $\mathrm{K}_{\text {ATP }}$ channels, ROS-signalling and prevention of MPTP opening, with a central role for upstream PI3K/Akt and PKCs. In fact, all inhibitors completely abolished CST-infarct-sparing effect. Since CST-anti-contracture effect cannot be explained by intra-mitochondrial mechanisms (PKCE activation and mitoK $_{\text {ATP }}$ channel opening) or ROS-signalling, it is proposed that these downstream signals are part of a reverberant loop which re-activates upstream PKCs, which therefore play a pivotal role in CST-induced protection.
\end{abstract}

Key words: Catestatin; Chromogranin A; Cardioprotection; Ischaemia/reperfusion; Postconditioning. 


\section{Introduction}

Rapid reperfusion is the gold-standard therapy for acute myocardial infarction (AMI). However reperfusion induces myocardial damages, which can be prevented by timing treatments in early reperfusion phase $[7,13,21,34,53]$. Reperfusion injury includes all forms of cell death as well as contractile dysfunction of surviving cells [7,13,34,53]. It has been shown that several peptides are able to induce cardioprotection when infused in the early reperfusion; that is pharmacological postconditioning [13,21,38,39]. These peptides, acting on their specific receptors, can trigger both pharmacological pre- and postconditioning via pro-survival intrinsic signalling pathways, which include in rodents the so called Reperfusion Injury Salvage Kinase (RISK) and Survivor Activating Factor Enhancement (SAFE) pathways [18,48].

Survival kinases, such as phosphatidylinositol-3-kinase (PI3K)/protein kinase B (Akt/PKB) and protein kinase $\mathrm{C}$ (PKC) may act on downstream mitochondrial targets to open ATP sensitive potassium ( mitoK $_{\text {ATP }}$ ) channels and to affect cellular survival, reducing both necrosis and apoptosis $[7,13,41,56]$. The mitoK $_{\text {ATP }}$ channels via multiple mechanisms, including the partial depolarization of the mitochondrial membrane, may favour reactive oxygen species (ROS)-signalling, which may lead to a re-activation of a pool of PKCs $[15,35,53]$. In particular, in concert with mitoK $\mathrm{ATP}_{\mathrm{ATP}}$ channels, the intramitochondrial protein kinase $\mathrm{C} \varepsilon(\mathrm{PKC \varepsilon})$ activation may take part to the so-called “memory-associated protection". Nevertheless, the signal transduction pathways for protection from lethal and non-lethal reperfusion injury are still under intense debate $[2,7,9,15,18,34]$

Recently, several biologically active peptides derived from chromogranin A ( $\mathrm{CgA})$, including Vasostatin-1 (VS-1) and Catestatin (CST), have received attention as regulators 
of cardiovascular function $[2,11,12,19,22,29,43]$. For instance, the N-terminal VS-1 induced a preconditioning-like effect via adenosine/nitric oxide (NO) protective signalling, reducing the extension of myocardial infarction in the rat heart [10].

The C-terminal CgA-derived peptide CST is a non-competitive antagonist of nicotineevoked catecholamine secretion $[17,29,32]$ and it induces vasodilatation through both inhibition of catecholamine release and increased circulating levels of histamine [22,23]. CST plasma levels are decreased not only in hypertensive patients but also in their stillnormotensive offspring [27-29,32]; accordingly, exogenous CST rescues arterial hypertension of $\mathrm{CgA}$ knockout mice [28]. CST also caused vasodilatation in human subjects with a NO-dependent mechanism [16]. Recently, on the isolated rat heart, CST was found to elicit a vasorelaxant influence on coronary arteries pre-contracted by endothelin-1, together with negative inotropic and lusitropic actions, counteracting the positive effects elicited by the $\beta$-adrenoceptor activator, isoproterenol [3]. CST inhibition of $\beta$-adrenoceptor activation in cardiomyocytes [3] is "presumably mediated by the relaxing effect of the endothelial cell-derived NO-release mediated by Akt/PKB signalling to endothelial NO synthase" [19]. Importantly, in AMI patients an initial reduction with a subsequent increase in CST plasma levels has been recently reported [55].

We have studied the cardioprotective effect of CST infused during the early reperfusion as pharmacological postconditioning (CST-Post) [36]. CST-Post reduced post-ischaemic myocardial contracture and significantly improved post-ischaemic recovery of contractility. Using isolated cardiac cells, we also reported that the protection observed is primarily due to a direct effect on the cardiomyocytes and does not necessarily depend on the endothelial effects of CST [36]. Since in multiple models $[39,41,42,51,52,56]$, including isolated cells $[48,51,56]$, an involvement of PI3K/Akt, PKCS, mitoK ATP channel and ROS-signalling have been observed in ischaemic 
postconditioning, we hypothesized that the CST-induced cardioprotective response in reperfusion may involve potential signalling proteins (e.g. PI3K/Akt and PKCs) and potential downstream

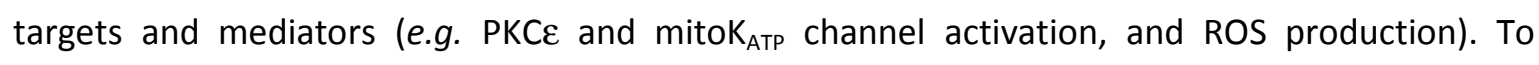
explore the role of these elements in the CST-Post-induced cardioprotection, we used Langendorff rat hearts reperfused in the presence of inhibitors of either PI3K/Akt, PKCs, PKCE or mitoK $_{\text {ATP }}$ channels or a ROS scavenger. Moreover, to corroborate the involvement of mitochondria in the CST-induced cardioprotection, we also studied CST protective role in cardiac cell line in the presence of oxidative stress, using a specific probe for the evaluation of intramitochondrial potential variation.

\section{Methods}

\subsection{Animals}

Male Wistar rats were used in accordance with the Italian law (DL-116, Jan. 27, 1992) and the Guide for the Care and Use of Laboratory Animals published by the US National Institutes of Health (NIH Publication No. 85-23, revised 1996). The project was approved by the Italian Ministry of Health, Rome, and by the ethics review board of the University of Turin. Adult rats were anaesthetized by i.p. injection of urethane $(1 \mathrm{~g} / \mathrm{kg})$ and killed by decapitation.

\subsection{Isolated heart perfusion}

The methods were similar to those previously described [1,33,35,36,39-41]. In brief, after anaesthesia chest was opened and heart excised. Hearts were immediately constant-flow perfused with Krebs-Henseleit buffer solution $(127 \mathrm{mM} \mathrm{NaCl}, 17.7 \mathrm{mM} \mathrm{NaHCO}$, $5.1 \mathrm{mM} \mathrm{KCl}, 1.5$ $\mathrm{mM} \mathrm{CaCl}_{2}, 1.26 \mathrm{mM} \mathrm{MgCl}, 11 \mathrm{mM}$ D-glucose (Sigma-Aldrich Corp., St. Louis, MO, USA) gassed with $95 \% \mathrm{O}_{2}$ and $5 \% \mathrm{CO}_{2}$. The hearts were instrumented to record coronary pressure and left 
ventricular pressure (LVP), electrically paced at 280 b.p.m. and kept in a temperature-controlled chamber $\left(37^{\circ} \mathrm{C}\right)[1,33,35,36,39-41]$.

\subsubsection{Cardiac function and Infarct-size studies}

After 40 min stabilization, hearts were subjected to $30-\mathrm{min}$, normothermic, zero-flow global ischaemia, followed by 120-min reperfusion (Group 1, l/R).

In a second Group (CST-Post group), CST (75nM) [36] was infused for 20-min at the beginning of reperfusion. Then the action of CST-Post was studied in the presence of specific inhibitors.

In Group 3 and 4, the large spectrum PKC inhibitor, chelerythrine ( $\mathrm{CHE}, 5 \mu \mathrm{M}$; CST-Post+CHE

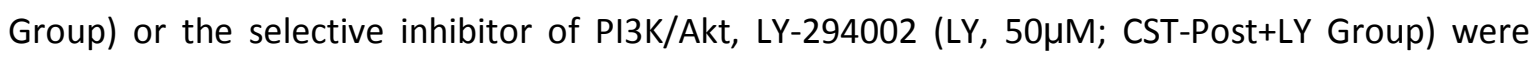
used to test the involvement of these pivotal kinases in cardioprotection scenario $[35,42]$.

In Group 5 a specific PKC $\varepsilon$ inhibitor, $\varepsilon$ V1-2, was used to test the involvement of this kinase $(\varepsilon \vee 1-2$ $1 \mu \mathrm{M}$; CST-Post+عV1-2 Group) [44].

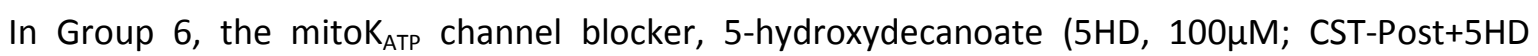
Group) [41 and references therein] was used to test whether the action of CST-Post could include mitoK $_{\text {ATP }}$ channel activation.

In Group 7, to confirm ROS involvement, we used a ROS scavenger, 2-mercaptopropionylglycine

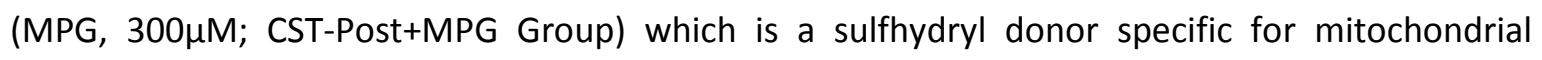
activity [30,39 and references therein].

Perfusion with inhibitors started 5-min before ischaemia and continued during the early 20-min of reperfusion in the presence of CST-Post ( $n=8$ for each group). The concentrations of inhibitors were chosen on the basis of data found in the literature $[14,35,39,41-44$ and references therein]. 
In preliminary experiments these doses of inhibitors did not affect basal cardiac performance. CST concentration was chosen on the basis of dose-response curve on infarct-size limitation [36].

\subsubsection{Additional experiments}

To determine the effects of the antagonists themselves, control hearts were infused 5-min before the global ischaemia and during the initial 20-min of reperfusion with one only of the antagonists (CHE, LY, عV1-2, 5HD or MPG, Groups 8-12, n= 6 for each group).

Moreover, in order to evaluate the effective role of CST in cardioprotection, in additional experiments, hearts were perfused with heat-inactivated CST [3] at the identical concentration of active CST (75nM), for 20-min at the beginning of reperfusion.

At the end of the experiments all the hearts were removed from the apparatus to evaluate the extension of infarct-size.

\subsection{Assessment of cardiac function}

A polyvinyl-chloride balloon was placed into the left ventricle (LV) and connected to the electromanometer filled with saline to obtain an end diastolic LVP of $5 \mathrm{mmHg}$. Such a volume of LV was maintained throughout the experiment [33,35,36,39-41].

Coronary perfusion pressure and LVP were monitored to assess the preparation conditions. LVP was analyzed offline with LabView software (National Instruments). Care was taken to measure LVP in a period (15-20 s) without arrhythmias.

\subsection{Assessment of myocardial injury}

Infarct areas were assessed at the end of the experiment as previously described $[32,34,35,38$ 40]. In brief, immediately after reperfusion hearts were rapidly removed from the perfusion 
apparatus and the LV dissected into 2-3 $\mathrm{mm}$ circumferential slices. Following $20 \mathrm{~min}$ of incubation at $37^{\circ} \mathrm{C}$ in $0.1 \%$ solution of nitro-blue tetrazolium in phosphate buffer, unstained necrotic tissue was carefully separated from stained viable tissue by an independent observer, who was unaware of the protocols. The necrotic mass was expressed as a percentage of total left ventricular mass. In fact, only the LV had a fixed volume and pre-load; therefore only the LV mass was considered as risk area, though in this model the whole heart underwent normothermic ischaemia.

\subsection{Oxidative stress and mitochondrial potential in $\mathrm{H} 9 \mathrm{c2}$}

2.5.1 Cell culture and drug treatment.

The cardiac myoblast H9C2 cell line (ATCC, CRL-1446) was maintained in DMEM supplemented with $15 \%$ heat-inactivated $\mathrm{FCS}, 100 \mathrm{U} / \mathrm{mL}$ penicillin and $100 \mu \mathrm{g} / \mathrm{mL}$ streptomycin sulphate in a humidified incubator at $37 \circ$ 을 under $5 \% \mathrm{CO}_{2} /$ air prior to use. $\mathrm{H} 9 \mathrm{c} 2$ cells were seeded in quadruplicate in 24-well plates and the experimental groups were: i) control: CTRL, absence of any additional treatment; ii) $\mathrm{H}_{2} \mathrm{O}_{2}$ : $\mathrm{H} 9 \mathrm{c} 2$ were exposed to $50 \mu \mathrm{M} \mathrm{H}_{2} \mathrm{O}_{2}$ for 2 hours [20]; iii) CST: cells were exposed to CST 75nM for 3 hours; iv) CST $+\mathrm{H}_{2} \mathrm{O}_{2}$ : cells were exposed to CST for 1 hour, then CST plus $\mathrm{H}_{2} \mathrm{O}_{2}$ were continued for other 2 hours.

2.5.2 Cell survival

The cell viability was determined by a colorimetric MTT assay, as described previously [54].

2.5.3 Measurement of mitochondrial potential

The quantification of mitochondrial potential variation was obtained with JC-1 during fluorimetric analysis [45]. In brief, JC-1 $(10 \mu \mathrm{M})$ was added to cultured cells [46] in control and after the 
treatment with $\mathrm{H}_{2} \mathrm{O}_{2}(50 \mu \mathrm{M})$ [20] with or without CST (75 nM). The ratio between red and green JC-1 florescence was taken as an index of mitochondrial membrane potential [25].

\subsection{Drugs}

CST was a generous gift of Dr. Sushil K. Mahata (University of California and Veterans Affairs San Diego Healthcare System, San Diego, California; USA). CHE, MPG, LY, and 5HD were purchased from Sigma (St. Louis, MO, USA); عV1-2 from AnaSpec Inc. (Fremont, California, USA).

\subsection{Statistical analysis}

All data are expressed as means \pm SEM. One-way ANOVA and Newman-Keuls multiple comparison tests (for post-ANOVA comparisons) have been used to compare infarct-size. Functional data were compared with repeated measures ANOVA (time/group). A $t$ test with Bonferroni correction was also used to compare the last-time points of functional data. Differences with $p<0.05$ were regarded as statistically significant.

\section{Results}

The baseline values of the considered parameters at the end of stabilization period were in the range of those usually used in this model. Specifically, a coronary perfusion pressure (CPP) of about $80 \mathrm{mmHg}$ was obtained adjusting the coronary flow (CF) to $9 \pm 1 \mathrm{ml} / \mathrm{min} / \mathrm{g}$, and an enddiastolic LVP (LVEDP) of about $5 \mathrm{mmHg}$ was achieved adjusting the volume of the balloon placed into the LV. Basal values of CPP and LVEDP did not change significantly throughout the stabilization period. At the end of stabilization, the hearts developed a LVP (dLVP) of about 80 $\mathrm{mmHg}$. 
3.1 CST-Post improved post-ischaemic cardiac function in a PI3K/Akt and PKCs dependent manner

3.1.1 Systolic function

In Fig 1, panel A, developed LVP data are reported as percent variation with respect to baseline level. In Fig 1, panel B, dLVP data are reported as area under the curve (AUC) during reperfusion.

The hearts of the I/R group showed a marked limitation of dLVP recovery during reperfusion; in fact, dLVP was $34 \pm 10 \%$ of baseline level at the end of reperfusion (dLVP decreased from $81 \pm 4$ to $28 \pm 6 \mathrm{mmHg} ; p<0.001$, this $p$ value is not reported in Fig $1 \mathrm{~A})$.

As can be seen in Fig $1 \mathrm{~A}$ and $1 \mathrm{~B}$, CST-Post markedly improved the dLVP recovery during reperfusion ( $p<0.01$ vs. I/R group); in particular, at the end of reperfusion dLVP was $111 \pm 13 \%$ of baseline levels. The co-infusion of antagonists of upstream signals, such as LY or CHE (inhibitors of PI3K/Akt and PKCS, respectively), along with CST abolished the cardioprotective effects of CSTPost (Fig 1A and 1B). However, the co-infusion of CST with antagonists of downstream signals, such as $\varepsilon V 1-2,5 H D$ or MPG (inhibitors of PKCE, mitoK ATP channels or ROS scavenger, respectively), partially reduced the protective effect of CST-Post. Statistical analysis yielded similar results whether are compared the last time points $\left(120^{\text {th }} \mathrm{min}\right.$ of reperfusion, Fig $\left.1 \mathrm{~A}\right)$ or the AUC (Fig 1B).

3.1.2 Diastolic function

In Fig 1, panel C, the levels of LVEDP are reported in $\mathrm{mmHg}$ throughout the entire experiment duration. In Fig 1, panel $D$, these data are reported as area under the curve (AUC) during reperfusion. Contracture can be defined as an increase in LVEDP of $4 \mathrm{mmHg}$ above the baseline level [5,33]. 
I/R induced a marked increase of LVEDP, which reached $54 \pm 14 \mathrm{mmHg}$ at the end of reperfusion $(p<0.001$ vs. baseline level; this $p$ value is not reported in Fig 1). CST-Post significantly limited the development of contracture occurring during reperfusion; at the end of reperfusion, in fact, LVEDP was $23 \pm 7 \mathrm{mmHg}$ ( $\mathrm{p}<0.01$ vs. $\mathrm{l} / \mathrm{R}$ ). Co-infusion with upstream antagonists (CHE or LY) abolished the protective effect of CST against contracture ( $p=$ NS vs. I/R last time point, Fig 1C). However, in the presence of these inhibitors ( $\mathrm{LY}$ or $\mathrm{CHE}$ ) the contracture development was somewhat slower than in I/R; in fact AUCs were smaller than I/R, though bigger than CST-Post (Fig 1D).

Yet the co-infusion with either $\varepsilon V 1-2,5 H D$ or MPG (downstream antagonists) did not abolish the contracture limitation induced by CST-Post ( $p<0.01$ vs. I/R last time point; $p=$ NS vs. CST-Post last time point, Fig 1C). Similar results were shown by analysis of AUCs (Fig 1D).

The cardiac function parameters observed in hearts perfused with only inhibitors (groups 8-12) or inactivated-CST during reperfusion were similar to those observed in I/R group (data not shown).

\subsection{CST-Post limited infarct-size through PKC and mitoK $K_{A T P}$ channel involvement}

The risk area, i.e., left ventricular mass, was similar in all groups. Infarct-size (Fig 2A), expressed as a percentage of LV mass, was $67 \pm 6 \%$ in I/R. CST-Post reduced infarct-size to $37 \pm 4 \%$ of $\mathrm{LV}$ mass $(\mathrm{p}<0.01 v s . \mathrm{I} / \mathrm{R})$. The co-infusion with either the upstream blockers (CHE or LY), or the downstream antagonists ( $\varepsilon V 1-2,5 \mathrm{HD}$ or MPG) abolished the protective effect of CST against infarct size (see Fig. 2A).

Risk area and infarct-size assessed in hearts perfused with only inhibitors (groups 8-12) were similar to those observed in I/R control group (Fig.2B). This lack of effects on I/R injury has been already reported [14,35,39,41-44]. 
The infusion of inactivated CST had no protective effects against infarct size $(64 \pm 4 \%, \mathrm{p}=$ NS vs. I/R, $\mathrm{p}<0.01$ vs. CST-Post).

\subsection{CST protected the cultured cells from oxidative stress}

Figure 3 shows the protective effects of CST against oxidative stress in the H9c2 cells. Oxidative stress with $\mathrm{H}_{2} \mathrm{O}_{2}$ significantly reduced the survival of $\mathrm{H} 9 \mathrm{c} 2$ cell ( $\mathrm{p}<0.05$ vs. Control group), and the co-treatment with CST abolished this effect (Fig 3A).

3.3.1 CST avoided mitochondrial membrane potential dissipation due to oxidative stress

As expected, $\mathrm{H}_{2} \mathrm{O}_{2}$ drastically reduced the mitochondrial potential $(\mathrm{p}<0.01$ vs. CTLR and CST groups), while the co-treatment $\left(\mathrm{CST}+\mathrm{H}_{2} \mathrm{O}_{2}\right)$ significantly limited this reduction ( $\mathrm{p}<0.05$ vs. $\mathrm{H}_{2} \mathrm{O}_{2}$ and CTLR groups) (Fig 3B). Of note, CST per se induced a partial, nonsignificant, depolarization of the mitochondrial membrane.

\section{Discussion}

The C-terminal fragment of Chromogranin A, CST, is known as an inhibitor of catecholamine secretion and a regulator of cardiovascular functions $[19,23,28]$. The cardiac activity of CST is achieved through signalling pathways expected for receptor-orphan peptides with membraneinteracting properties [4]. Here, using classic antagonists [14,35,39,41-44], we demonstrated for the first time that the cardioprotective effect of CST-Post depends on the activation of PI3k/Akt,

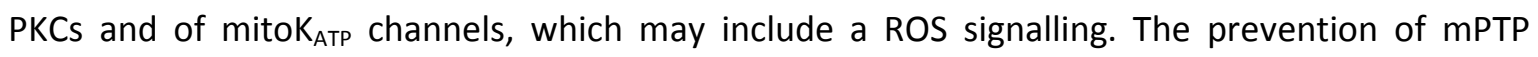
opening in myocytes challenged with oxidative stress reinforces the idea that CST protective effects converge on mitochondria.

Most studies with cardioprotective agents have addressed either the post-ischaemic mechanical recovery or the reduction of the infarct-size. Thus it remains unclear whether the mechanical 
recovery is attributable to the reduction of infarct-size only and/or to a direct effect of the cardioprotective agent on post-ischaemic mechanical function of myocardium. Here, we show that CST-Post significantly reduces both the extension of infarct-size and the myocardial contracture development drastically improving post-ischaemic systolic function during reperfusion (see Fig 1). Importantly, the distinct inhibitors targeting different elements of the protective pathway allow dissecting the effect on mechanical function and cell death. In fact, in the present study, all the antagonists used abrogate CST-Post protection against infarct-size development (Fig 2). However, the post-ischaemic contractile function was differently affected by antagonists of upstream and downstream targets of CST in the protective signalling pathway (Fig 1 and Fig 4).

CST-cardioprotective effects against infarct size were abolished by either upstream antagonists, namely the broad range inhibitor of PKCs, CHE, or the PI3K/Akt antagonist, LY, as well as by the downstream target antagonists, namely the specific PKC $\varepsilon$ antagonist, $\varepsilon V 1-2$, the mitoK ${ }_{\text {ATP }}$ channel blocker, 5HD, or the ROS scavenger, MPG. This supports the viewpoint that the activation of pathways both outside (PI3K/Akt and pool of PKCS) and inside the mitochondria (PKCE activation, mitoK $_{\text {ATP }}$ channel opening and subsequent ROS diffusion) are required for CST-induced protection against infarct size.

With respect to contracture development, we observed that its limitation by CST can only be slowed down in the presence of CHE and LY, but can be still reduced in the presence of the downstream target inhibitors ( $\varepsilon V 1-2,5 H D$ and MPG.) In other words, while CHE and LY were able to limit CST-induced contracture protection, $\varepsilon V 1-2,5 H D$ or MPG (antagonists of mitochondrial factors) were not able to limit the protective effect of CST against contracture development. This suggests that the CST-induced limitation of contracture is mitochondrial-independent. Possible 
mechanisms include CST-induced phospholamban phosphorylation, as shown by Angelone et al [4].

It may be stressed that PKC $\mathrm{P}$-dependent cardioprotection is mainly due to its mitochondrial activity. In fact, under I/R conditions mitochondrial translocation of PKCE occurs rapidly, with a corresponding decline in cytosolic PKC $\varepsilon$ levels [9]. Moreover, a number of cardioprotective stimuli enhance mitochondrial translocation of $\mathrm{PKC} \varepsilon$, which may mediate protection via the phosphorylation of intramitochondrial proteins [9 and references therein]. Therefore, it is not a surprise that the specific PKC $\varepsilon$ inhibitor, $\varepsilon V 1-2$, affects mitochondrial-dependent protection.

Although several authors report that the ROS scavenger, MPG, given in reperfusion does not affect infarct size $[13,14,26,34,39]$, it is currently unknown why the addition of MPG does not elicit any protection, but may limit cardioprotective efficacy of various protective interventions $[13,14,26,34,39]$. The most likely explanation is that the ROS signal is carried by specific radical species and/or in specific intracellular compartment $[26,40]$. MPG, which concentrates 500 -fold in mitochondria and is highly effective against some mitochondrial ROS $[26,30]$, evidently, is able to scavenge the few radical species that signal the protection, but is not effective against I/R injury due to massive ROS production $[13,14,26,30,34,39]$.

We suggest that the activation of the PKCs pool is a pivotal step in CST-Post cardioprotection; in fact the co-infusion with CHE abolishes all CTS-Post-elicited protective effects (Figs 1 and 2). Likely, the mitoK $\mathrm{K}_{\text {ATP }}$ channel opening with subsequent ROS formation signalling is implicated in the CST-Post induced protection $[13,15,31]$. In fact ROS can activate a redundant pool of kinases involved in cardioprotection $[7,13,18,35,41]$, including PKCs, thus eliciting a positive feed-back loop [47], which may provide a sort of cardioprotection memory (reverberant loop, Fig 4) [15]. In fact $\varepsilon V 1-2$ and MPG, similarly to 5HD, only partially block the CST protective effects. Hence, we can argue that the above described memory effect is necessary for limiting the infarct, but less 
important for post-ischaemic contracture limitation. In fact, contracture limitation persists in $\varepsilon V 1$ -

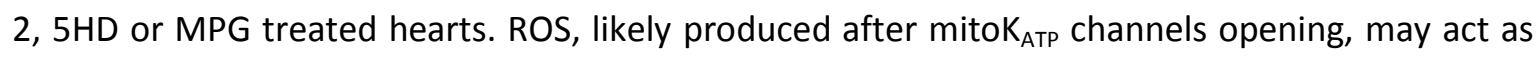
double edge swords; that is, they may act as second messengers to trigger the pathway of protective kinases, being at the same time involved in mediating part of myocardial dysfunction $[7,34,38]$

While the PKCs pool plays a pivotal role in the protective effects (see for instance the cardioprotective effect of the large spectrum PKC activator, 4 beta-phorbol 12-myristate 13acetate (PMA) [26], and our data with the large spectrum PKC inhibitor, CHE), the PKCE isoenzyme is only part of the reverberant loop. In fact, as said, the specific PKCE inhibitor, $\varepsilon V 1-2$, does not counteract the CST-induced contracture limitation.

Theoretically, the improved systolic function might be due to the limitation of infarct-size and contracture, as well as to a direct CST induced anti-stunning effect. However, the long-lasting post-ischaemic systolic recovery in CST-Post experiments could not be explained by the inotropic effect of CST, which is known to exert transient (a few minutes) positive [6] and prolonged negative inotropic effects in normoxia $[4,6]$. Therefore, the CST-induced improvement of postischaemic systolic function can be attributed to both the limitation of infarct-size and the prevention of contracture [36].

CST exerted direct protective effect against simulated I/R in isolated adult cardiomyocytes [36]. Of note, here, we show CST-protection on myocardial cell line, in which CST may induce a partial mitochondrial depolarization. Since the latter is considered part of the protective response of the targeted mitochondria $[15,35,53]$, it is intriguing that CST may protect these cells against oxidative injury and excessive mitochondrial depolarization (Fig 3). Nevertheless, a cross-talk between endothelium and myocardium may play a role in the peptide induced protection [40], 
since the CST inotropic and anti-adrenergic effects have been attributed to a PI3K/Akt-dependent NO release from endothelial cells $[4,6]$.

It has been reported that under certain conditions CST may exert deleterious effects and does not activate Akt [8]. Our results demonstrate that the CST-elicited cardioprotection is PI3K/Aktdependent, being abolished by the co-infusion of CST plus LY. It can be argued that the use of different models of ischaemia (e.g., global vs. regional ischaemia) and/or the dose/duration of treatment may be the cause of these conflicting results. In fact, depending on the conditions used, several substances may be protective or deleterious $[13,35,37]$, as we and others have observed for other mediators such as platelet-activating factor [24,35,37] and Angeli's salt, which are protective in pre- but not in postconditioning [32,33,37,38 and references therein].

In conclusion, our study demonstrates that CST-Post significantly reduces infarct-size and improves post-ischaemic cardiac function in isolated constant-flow perfused rat hearts; these

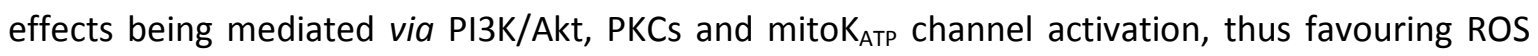
signalling. By inhibiting alternatively PKC $\varepsilon$ only or various PKC isoforms, as well as signal elements

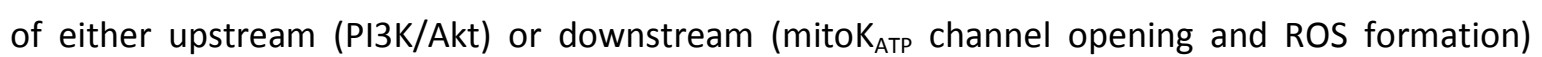
protective pathway, we have identified distinct components implicated in CST protection against infarct size and post-ischaemic contractile dysfunction.

Clinical considerations

The reported delayed increase of CST levels after infarction [55] may be implicated in the compensatory response against myocardial injury. Pharmacological postconditioning, which, however, target the first few minutes of reperfusion, may be clinically useful at the time of angioplasty, thrombolysis or cardiac surgery.

Actually, CST is known to counteract exaggerated $\beta$-adrenergic activity, which is relevant part of 
the neuroendocrine scenario of heart failure [1-4], and to dilate human vessels in vivo [16], thus exerting positive effects on cardiac afterload. In line with these evidences and since $\beta$-blockade is largely used as post-ischaemic treatment, the present work suggests that exogenous CST may provide new tool for pharmacological postconditioning.

\section{Acknowledgements}

The authors wish to thank Prof. Donatella Gattullo for insightful suggestions, and Dr. Sushil K. Mahata for providing us with CST. This work was supported by National Institute for Cardiovascular Research (INRC-2010, to BT, GA, MCC, PP); Regione Piemonte (CP, GA, PP), ex-60\% (CP, PP, GA) and PRIN-2008 (BT, CP).

Conflict of interest: none declared. 


\section{References}

1. Angelone T, Filice E, Quintieri AM, et al (2008) Beta3-adrenoceptors modulate left ventricular relaxation in the rat heart via the NO-cGMP-PKG pathway. Acta Physiol (Oxf) 193: 229-239. doi: 10.1111/j.1748-1716.2008.01838.x

2. Angelone T, Mazza R, Cerra MC (2012) Chromogranin-A: a multifaceted cardiovascular role in health and disease. Curr Med Chem 19: 4042-4050. doi: 10.2174/092986712802430009

3. Angelone T, Quintieri AM, Brar BK, et al (2008) The antihypertensive chromogranin A peptide catestatin acts as a novel endocrine/paracrine modulator of cardiac inotropism and lusitropism. Endocrinology 149: 4780-4793. doi: 10.1210/en.2008-0318

4. Angelone T, Quintieri AM, Pasqua T, et al (2012) Phosphodiesterase type-2 and NO-dependent SNitrosylation mediate the cardioinhibition of the anti-hypertensive Catestatin. Am J Physiol Heart Circ Physiol 302: H431-H442. doi: 10.1152/ajpheart.00491.2011

5. Baker JE, Konorev EA, Gross GJ, Chilian WM, Jacob HJ (2000) Resistance to myocardial ischaemia in five rat strains: is there a genetic component of cardioprotection? Am J Physiol Heart Circ Physiol 278: H1395-H1400.

6. Bassino E, Fornero S, Gallo MP, et al (2011) A novel Catestatin induced antiadrenergic mechanism triggered by the endothelial PI3K-eNOS pathway in the myocardium. Cardiovasc Res 91: 617-624. doi: $10.1093 /$ cvr/cvr129

7. Boengler K, Heusch G, Schulz R (2011) Mitochondria in postconditioning. Antioxid Redox Signal 14: 863-880. doi:10.1089/ars.2010.3309

8. Brar BK, Helgeland E, Mahata SK, et al (2010) Human catestatin peptides differentially regulate infarct-size in the ischaemic-reperfused rat heart. Regul Pept 165: 63-70. doi: 10.1016/j.regpep.2010.07.153 
9. Budas GR, Churchill EN, Disatnik MH, Sun L, Mochly-Rosen D (2010) Mitochondrial import of PKCepsilon is mediated by HSP90: a role in cardioprotection from ischaemia and reperfusion injury. Cardiovasc Res 88: 83-92. doi:10.1093/cvr/cvq154

10. Cappello S, Angelone T, Tota B, et al (2007) Human recombinant chromogranin A-derived vasostatin-1 mimics preconditioning via an adenosine/nitric oxide signaling mechanism. Am J Physiol Heart Circ Physiol 293: H719-H127. doi: 10.1152/ajpheart.01352.2006

11. Ceconi C, Ferrari R, Bachetti T, et al (2002) Chromogranin A in heart failure; a novel neurohumoral factor and a predictor for mortality. Eur Heart J 23: 967-974. doi: 10.1053/euhj.2001.2977

12. Cerra MC, Gallo MP, Angelone T, et al (2008) The homologous rat chromogranin A1-64 (rCgA164) modulates myocardial and coronary function in rat heart to counteract adrenergic stimulation indirectly via endothelium-derived nitric oxide. FASEB J 22: 3992-4004. doi: 10.1096/fj.08-110239

13. Cohen MV, Downey JM (2011) Ischaemic postconditioning: from receptor to end-effector. Antioxid Redox Signal 14: 821-831. doi:10.1089/ars.2010.3318

14. Cohen MV, Yang XM, Downey JM (2007) The pH hypothesis of postconditioning: staccato reperfusion reintroduces oxygen and perpetuates myocardial acidosis. Circulation 115: 18951903. doi: 10.1161/CIRCULATIONAHA.106.675710

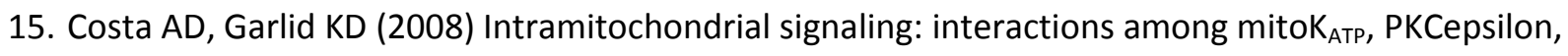
ROS, and MPT. Am J Physiol Heart Circ Physiol 295: H874-H882. doi: 10. 1152/ajpheart.01189.2007

16. Fung MM, Salem RM, Mehtani P, et al (2010) Direct vasoactive effects of the chromogranin A (CHGA) peptide catestatin in humans in vivo. Clin Exp Hypertens 32: 278-287. doi: $10.3109 / 10641960903265246$ 
17. Gaede AH, Pilowsky PM (2011) Catestatin, a chromogranin A derived peptide, is sympathoinhibitory and attenuates sympathetic barosensitivity and the chemoreflex in rat CVLM. Am J Physiol Regul Integr Comp Physiol 302: R365-R372. doi: 10.1152/ajpregu.00409.2011

18. Hausenloy DJ, Lecour S, Yellon DM (2011) Reperfusion Injury Salvage Kinase and Survivor Activating Factor Enhancement prosurvival signaling pathways in ischaemic postconditioning: two sides of the same coin. Antioxid Redox Signal 14: 893-907. doi:10.1089/ars.2010.3360.

19. Helle KB (2010) The chromogranin A-derived peptides vasostatin-I and catestatin as regulatory peptides for cardiovascular functions. Cardiovasc Res 85: 9-16. doi: 10.1093/cvr/cvp266

20. Ihara Y, Urata Y, Goto S, Kondo T. (2006) Role of calreticulin in the sensitivity of myocardiac H9c2 cells to oxidative stress caused by hydrogen peroxide. Am J Physiol Cell Physiol. 290:C208-C221. doi: 10.1152/ajpcell.00075.2005

21. Ivanès F, Rioufol G, Piot C, Ovize M (2011) Postconditioning in acute myocardial infarction patients. Antioxid Redox Signal 14: 811-820. doi:10.1089/ars.2010.3354.

22. Jansson AM, Røsjø H, Omland T, et al (2009) Prognostic value of circulating chromogranin A levels in acute coronary syndromes. Eur Heart J 30: 25-32. doi: 10.1093/eurheartj/ehn513.

23. Kennedy BP, Mahata SK, O'Connor DT, Ziegler MG (1998) Mechanism of cardiovascular actions of the chromogranin A fragment catestatin in vivo. Peptides 19: 1241-1248. doi.org/10.1016/S01969781(98)00086-2.

24. Leary PJ, Rajasekaran S, Morrison RR, Tuomanen El, Chin, TK, Hofmann PA (2008). A cardioprotective role for platelet-activating factor through NOS-dependent S-nitrosylation. Am J Physiol Heart Circ Physiol 294: H2775-H2784. doi:10.1152/ajpheart.00269.2008.

25. Liu J, Mao W, Ding B, Liang CS. (2008) ERKs/p53 signal transduction pathway is involved in doxorubicin-induced apoptosis in H9c2 cells and cardiomyocytes. Am J Physiol Heart Circ Physiol 295: H1956-H1965. doi: 10.1152/ajpheart.00407.2008 
26. Liu Y, Yang XM, Iliodromitis EK, et al (2008) Redox signaling at reperfusion is required for protection from ischemic preconditioning but not from a direct PKC activator. Basic Res Cardiol 103:54-59. doi: 10.1007/s00395-007-0683-y

27. Mahapatra NR (2008) Catestatin is a novel endogenous peptide that regulates cardiac function and blood pressure. Cardiovasc Res 80: 330-338. doi: 10.1093/cvr/cvn155

28. Mahapatra NR, O'Connor DT, Vaingankar SM, et al (2005) Hypertension from targeted ablation of chromogranin A can be rescued by the human ortholog. J Clin Invest 115: 1942-1952. doi: $10.1172 / \mathrm{JCl} 24354$

29. Mahata SK, Mahata M, Fung MM, O'Connor DT (2010) Catestatin: a multifunctional peptide from chromogranin A. Regul Pept 162: 33-43. doi.org/10.1016/j.regpep.2010.09.007

30. Nadtochiy SM, Burwell LS, Brookes PS (2007) Cardioprotection and mitochondrial S-nitrosation: effects of S-nitroso-2-mercaptopropionyl glycine (SNO-MPG) in cardiac ischemia-reperfusion injury. J Mol Cell Cardiol 42:812-825. doi: 10.1016/j.yjmcc.2007.01.010

31. Nishida H, Sato T, Ogura T, Nakaya H (2009) New aspects for the treatment of cardiac diseases based on the diversity of functional controls on cardiac muscles: mitochondrial ion channels and cardioprotection. J Pharmacol Sci 109: 341-347. doi:10.1254/jphs.08R24FM

32. O'Connor DT, Kailasam MT, Kennedy BP, Ziegler MG, Yanaihara N, Parmer RJ (2002) Early decline in the catecholamine release-inhibitory peptide catestatin in humans at genetic risk of hypertension. J Hypertens 20: 1335-1345

33. Pagliaro P, Mancardi D, Rastaldo R, et al (2003) Nitroxyl affords thiol-sensitive myocardial protective effects akin to early preconditioning. Free Radic Biol Med 34: 33-43. doi.org/10.1016/S0891-5849(02)01179-6

34. Pagliaro P, Moro F, Tullio F, Perrelli M-G, Penna C (2011) Cardioprotective pathways during reperfusion: focus on redox signaling and other modalities of cell signaling. Antioxid Redox Signal 14: 833-850. doi:10.1089/ars.2010.3245. 
35. Penna C, Alloatti G, Cappello S, et al (2005). Platelet-activating factor induces cardioprotection in isolated rat heart akin to ischaemic preconditioning: role of phosphoinositide 3-kinase and protein kinase C activation. Am J Physiol Heart Circ Physiol 288: H2512-H2520. doi: 10.1152/ajpheart.00599.2004

36. Penna C, Alloatti G, Gallo MP, et al (2010) Catestatin improves post-ischaemic left ventricular function and decreases ischaemia/reperfusion injury in heart. Cell Mol Neurobiol 30: 1171-1179. doi:10.1007/s10571-010-9552-6.

37. Penna C, Bassino E, Alloatti G (2011) Platelet activating factor: the good and the bad in the ischaemic/reperfused heart. Exp Biol Med (Maywood) 236: 390-401. doi: 10.1258/ebm.2011.010316

38. Penna C, Mancardi D, Raimondo S, Geuna S, Pagliaro P (2008) The paradigm of postconditioning to protect the heart. J Cell Mol Med 12: 435-458. doi: 10.1111/j.1582-4934.2007.00210.x

39. Penna C, Mancardi D, Rastaldo R, Losano G, Pagliaro P (2007) Intermittent activation of bradykinin $B_{2}$ receptors and mitochondrial $K_{\text {ATP }}$ channels trigger cardiac postconditioning through redox signaling. Cardiovasc Res 75: 168-177. doi:10.1016/j.cardiores.2007.03.001

40. Penna C, Perrelli MG, Tullio F, et al (2011) Postischaemic early acidosis in cardiac postconditioning modifies the activity of antioxidant enzymes, reduces nitration, and favors protein S-nitrosylation. Pflugers Arch 462: 219-233. doi: 10.1007/s00424-011-0970-1

41. Penna C, Rastaldo R, Mancardi D, et al (2006) Post-conditioning induced cardioprotection requires signaling through a redox-sensitive mechanism, mitochondrial ATP-sensitive $\mathrm{K}^{+}$channel and protein kinase C activation. Basic Res Cardiol 101:180-189. doi: 10.1007/s00395-006-0584-5

42. Philipp S, Yang XM, Cui L, Davis AM, Downey JM, Cohen MV (2006) Postconditioning protects rabbit hearts through a protein kinase $\mathrm{C}$-adenosine $\mathrm{A} 2 \mathrm{~b}$ receptor cascade. Cardiovasc Res 70 : 308-314. doi:10.1016/j.cardiores.2006.02.014 
43. Pieroni M, Corti A, Tota B, et al (2007) Myocardial production of chromogranin A in human heart: a new regulatory peptide of cardiac function. Eur Heart J 28: 1117-1127. doi: 10.1093/eurheartj/ehm022

44. Pravdic D, Sedlic F, Mio Y, et al (2009) Anesthetic-induced preconditioning delays opening of mitochondrial permeability transition pore via protein Kinase C-epsilon-mediated pathway. Anesthesiology 111: 267-274. doi: 10.1097/ALN.0b013e3181a91957

45. Rana P, Nadanaciva S, Will Y. (2011) Mitochondrial membrane potential measurement of H9c2 cells grown in high-glucose and galactose-containing media does not provide additional predictivity towards mitochondrial assessment. Toxicol In Vitro. 25:580-587. doi.org/10.1016/j.tiv.2010.11.016

46. Sathishkumar K, Gao X, Raghavamenon AC, et al (2010) Determination of glutathione, mitochondrial transmembrane potential, and cytotoxicity in H9c2 cardiomyoblasts exposed to reactive oxygen and nitrogen species. Methods Mol Biol. 2010;610:51-61. doi: 10.1007/978-160327-029-8_4

47. Shi J, Xu J, Zhang X, Yang L. (2012) Positive feedback induced memory effect in ischemic preconditioning. J Theor Biol. 300:317-323. doi.org/10.1016/j.jtbi.2012.01.033

48. Sivaraman V, Mudalgiri NR, Di Salvo C, et al (2007) Postconditioning protects human atrial muscle through the activation of the RISK pathway. Basic Res Cardiol 102: 453-459. doi: $10.1007 /$ s00395-007-0664-1

49. Sun HY, Wang NP, Kerendi F, et al (2005) Hypoxic postconditioning reduces cardiomyocyte loss by inhibiting ROS generation and intracellular Ca2+ overload. Am J Physiol Heart Circ Physiol 288: H1900- H1908. doi:10.1152/ajpheart.01244.2003

50. Theurl M, Schgoer W, Albrecht K, et al (2010) The neuropeptide catestatin acts as a novel angiogenic cytokine via a basic fibroblast growth factor-dependent mechanism. Circ Res 107:1326-1335. doi: 10.1161/CIRCRESAHA.110.219493 
51. Thuc LC, Teshima $\mathrm{Y}$, Takahashi N, et al (2010) Mitochondrial $\mathrm{K}_{\text {(ATP) }}$ channels-derived reactive oxygen species activate pro-survival pathway in pravastatin-induced cardioprotection. Apoptosis 15: 669-678. doi: 10.1007/s10495-010-0473-0

52. Tsutsumi YM, Yokoyama T, Horikawa Y, et al (2007) Reactive oxygen species trigger ischemic and pharmacological postconditioning: In vivo and in vitro characterization. Life Sci 81: 1223-12237. doi.org/10.1016/j.Ifs.2007.08.031

53. Vinten-Johansen J, Granfeldt A, Mykytenko J, et al (2011) The multidimensional physiological responses to postconditioning. Antioxid Redox Signal 14: 791-810. doi:10.1089/ars.2010.3396

54. Wang $X$, Willenbring $H$, Akkari $Y$, et al (2003) Cell fusion is the principal source of bone-marrowderived hepatocytes. Nature 422: 897-901. doi:10.1038/nature01531

55. Wang $\mathrm{X}, \mathrm{Xu} \mathrm{S}$, Liang $\mathrm{Y}$, et al (2011) Dramatic changes in catestatin are associated with hemodynamics in acute myocardial infarction. Biomarkers 16: 372-377. doi:10.3109/1354750X.2011.578260

56. Zatta AJ, Kin H, Lee G, et al (2006) Infarct-sparing effect of myocardial postconditioning is dependent on protein kinase C signaling. Cardiovasc Res 70: 315-324. doi:10.1016/j.cardiores.2005.11.030 


\section{Figure Legends}

\section{Fig 1. Cardiac performance.}

A Percent variation of developed LVP (dLVP) during the 30-min ischaemia (delimited by two vertical dashed lines) and the 120-min reperfusion; data are presented as percent changes with respect to baseline level for each group.

B Area under the curve (AUC): dLVP recovery during the 120 min of reperfusion (a.u.: arbitrary units).

C Left ventricular end-diastolic pressure (LVEDP) during the 30 -min ischaemia (delimited by two vertical dashed lines) and the 120-min reperfusion; data are expressed in $\mathrm{mmHg}$.

D Area under the curve (AUC): LVEDP recovery during the 120 min of reperfusion (a.u.: arbitrary units).

${ }^{*} \mathrm{p}<0.01$ vs. all groups; $\# \mathrm{p}<0.05$ vs. I/R and CST-Post-CHE; ${ }^{\circ} \mathrm{p}<0.05$ vs. CST-Post; $\S p<0.05 ;$ NS: not significant.

Fig 2. Infarct-size.

The amount of necrotic tissue is expressed as percent of the left ventricle (\% IS/LV), which is considered the risk area. A Effects of CST-Post with and without antagonists. B Effects of antagonists only (for comparative purpose are also reported I/R and CST-Post groups).

$*^{*} \mathrm{p}<0.01$ with respect to I/R; NS: not significant. 
Fig 3. Oxidative stress and mitochondrial potential in H9c2.

A Effects of $\mathrm{H}_{2} \mathrm{O}_{2}$ on the cell survival with and without CST; B Measurement of mitochondrial potential with JC-1 in $\mathrm{H} 9 \mathrm{c} 2$ in the presence and in the absence of $\mathrm{H}_{2} \mathrm{O}_{2}$ with and without CST. Data presented are mean values \pm SEM of four experiments.

${ }^{*} p<0.05$ vs. all groups; ${ }^{* *} p<0.01$ vs. all groups; $\# p<0.05$ vs. Control and $\mathrm{H}_{2} \mathrm{O}_{2}$

Fig 4. Hypothetical scheme outlining the 'reverberant' pathway between PKCE and mitoK ATP $_{\text {. }}$ channels, at the time of reperfusion, in response to CST-Post.

The hypothetical reverberant protective pathway may converge on the pivotal PKCs. This may explain why the inhibition of the main pathway using $\mathrm{CHE}$, the inhibitor of PKCs, abolishes all the protective effects, whereas blockade of mito $\mathrm{K}_{\mathrm{ATP}}$ channels with $5 \mathrm{HD}$ and PKC $\varepsilon$ with $\varepsilon \mathrm{V} 1-2$, as well as the ROS scavenger MPG can limit only part of the cardioprotective effects. For further explanations, see text. 
A

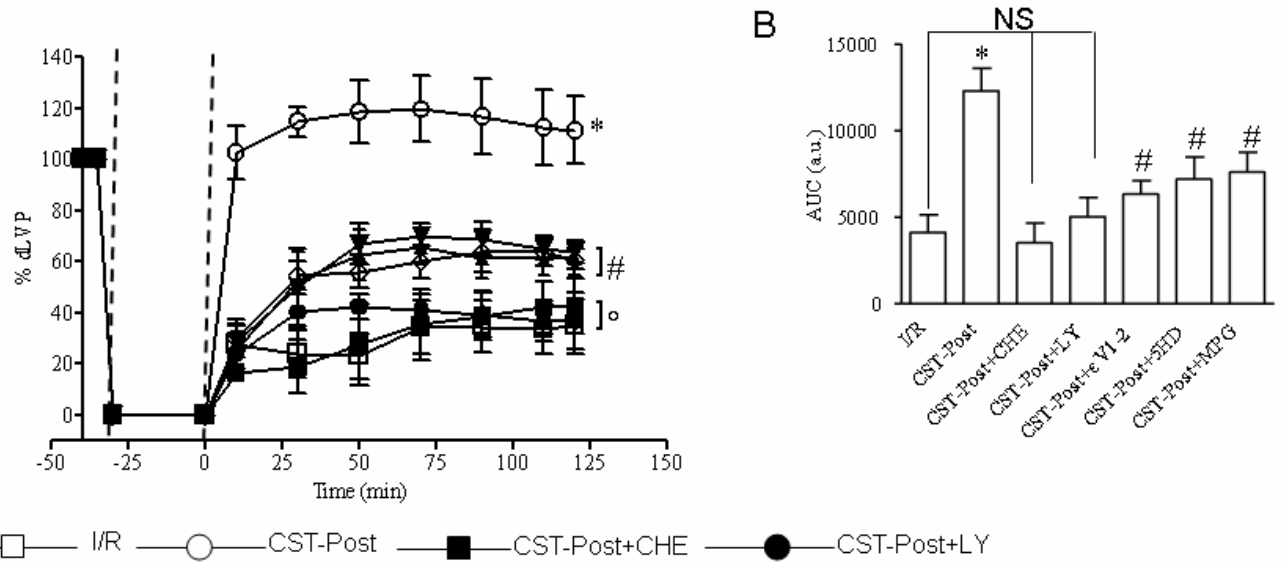

$\square$ IR $\longrightarrow$ IR CST-Post $\longrightarrow$ CST-Post +CHE $\longrightarrow$ CST-Post+LY

$\Delta$ CST-Post $+\varepsilon_{11-2} \longrightarrow$ CST-Post $+5 H D \longrightarrow$ CST-Post + MPG

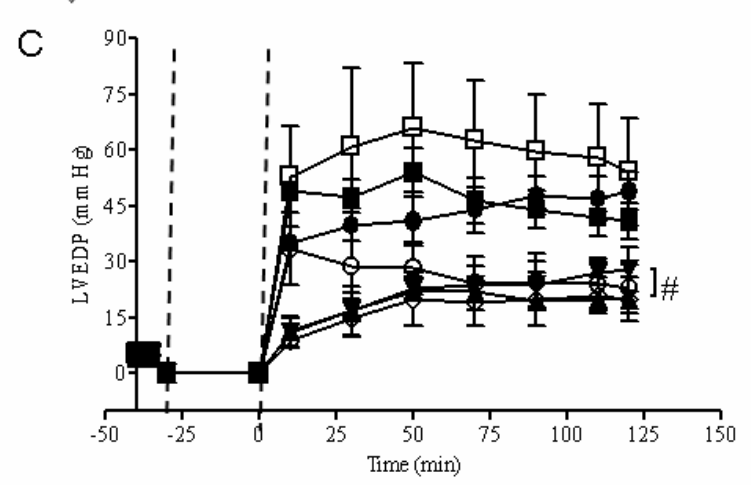

D 8000

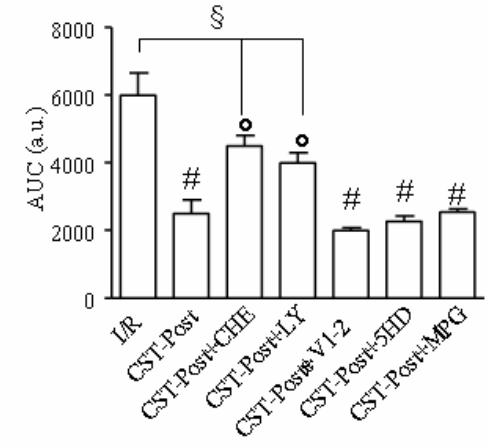




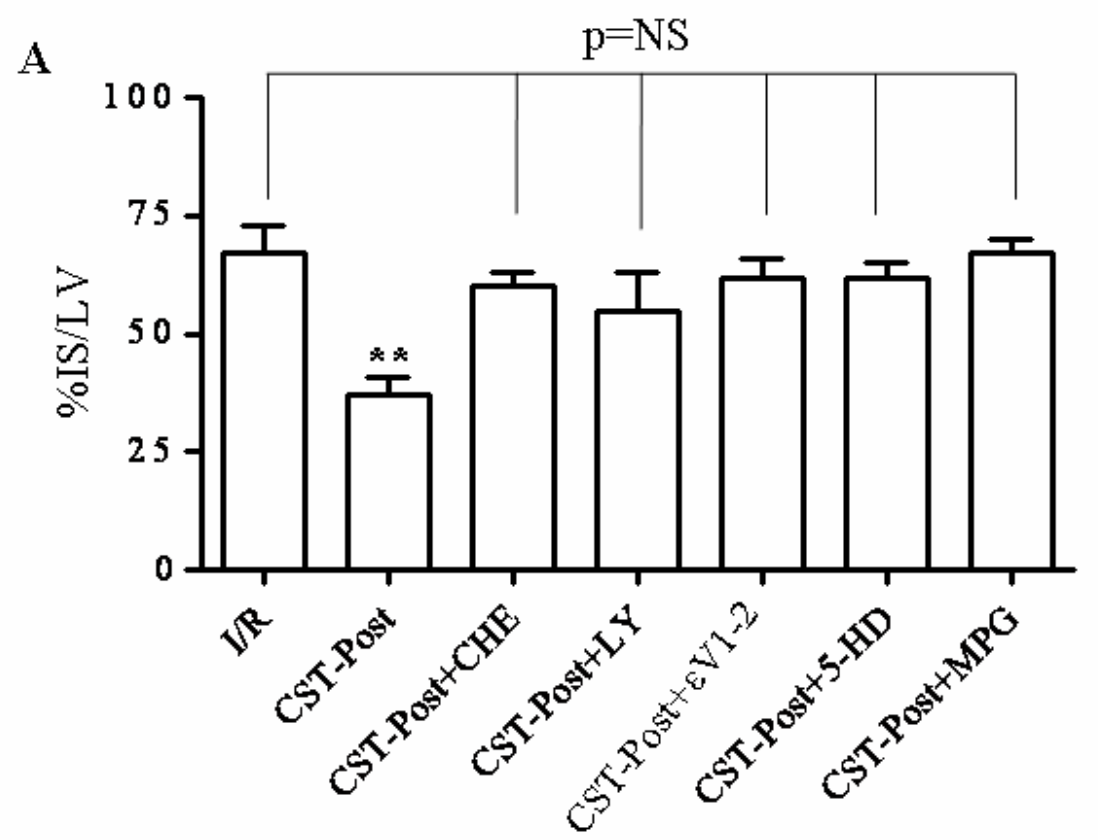

B

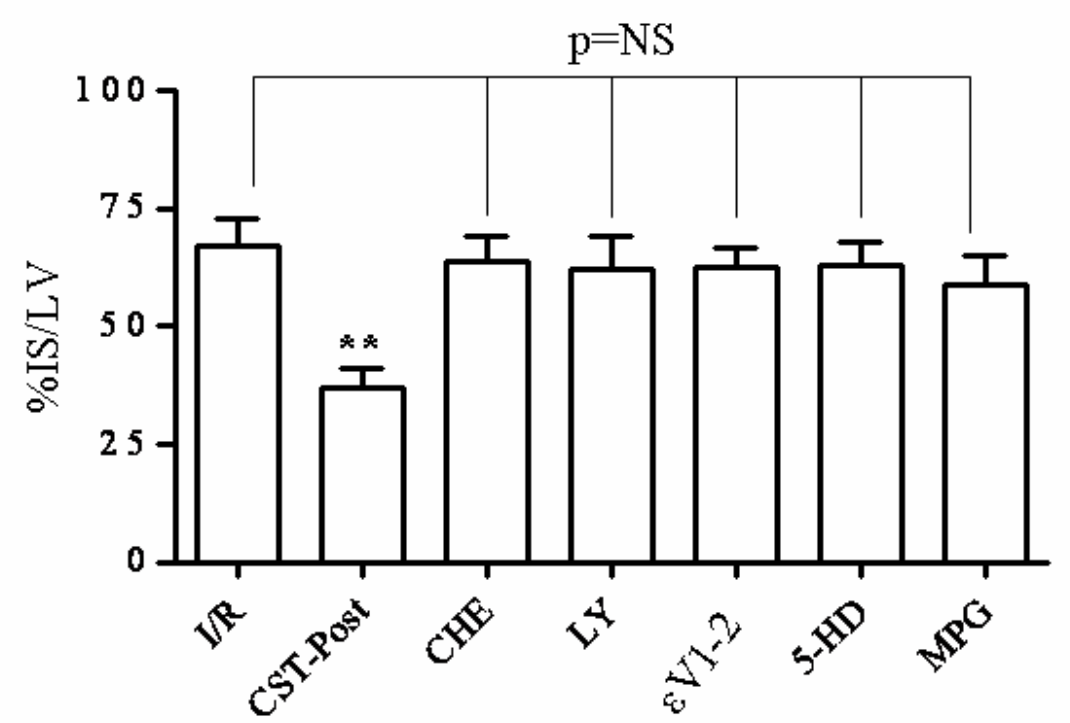

Fig. 2 
A

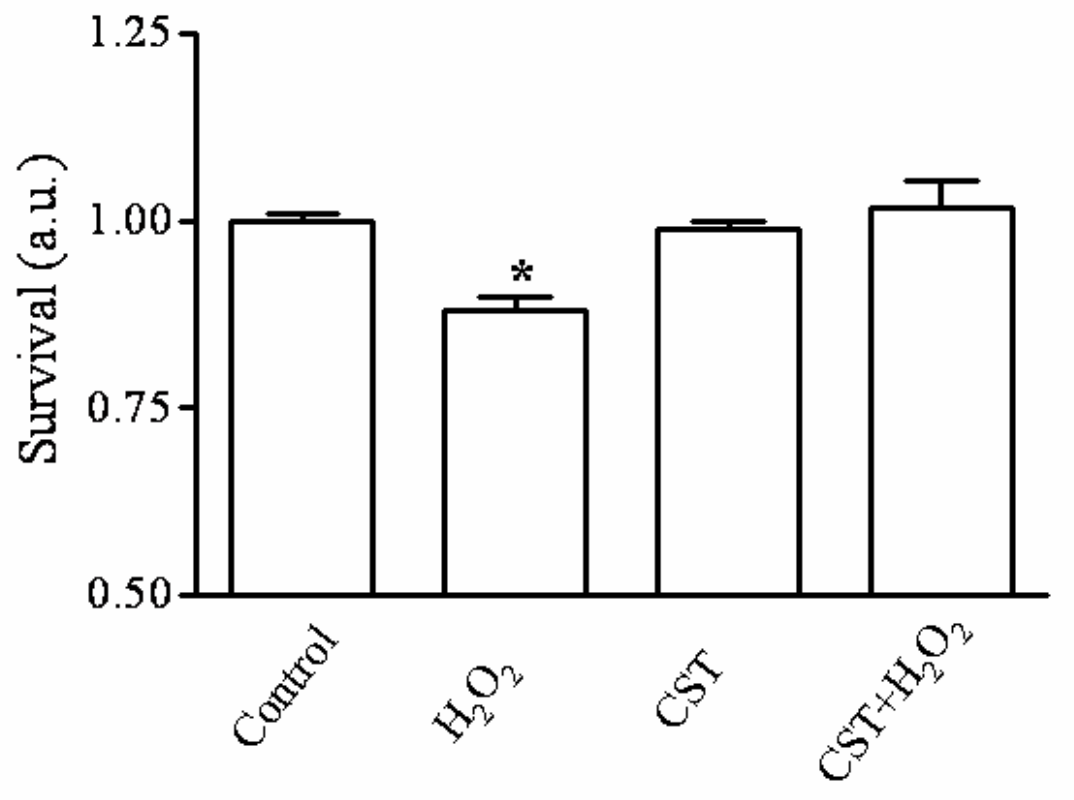

B

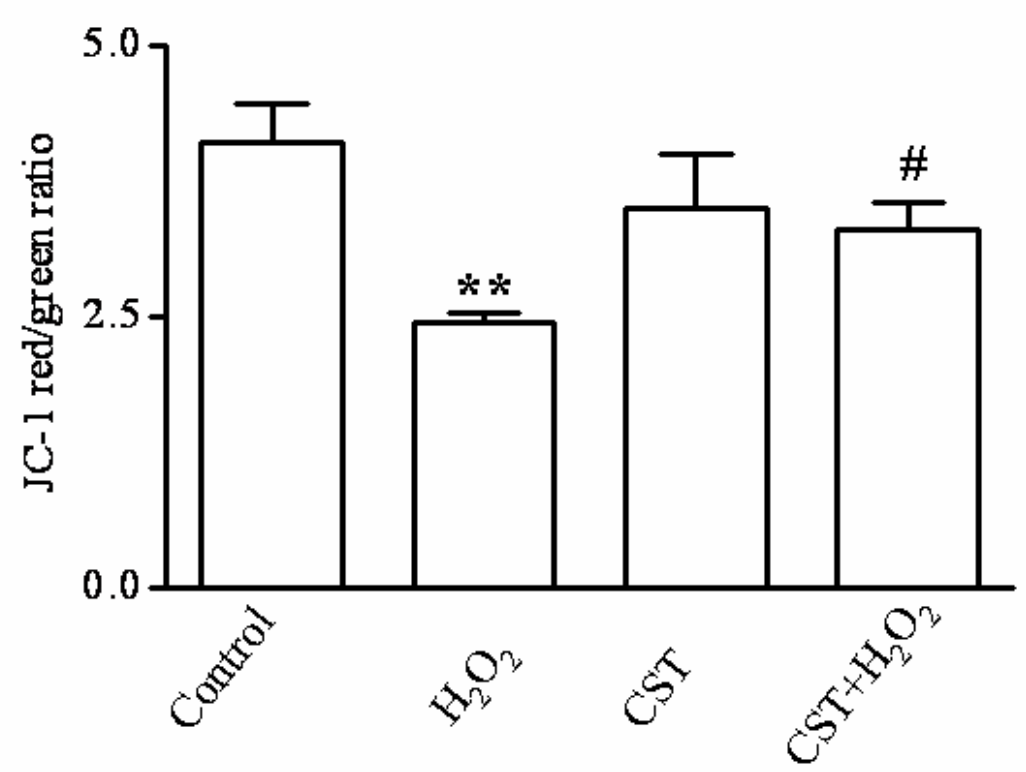

Fig.3 


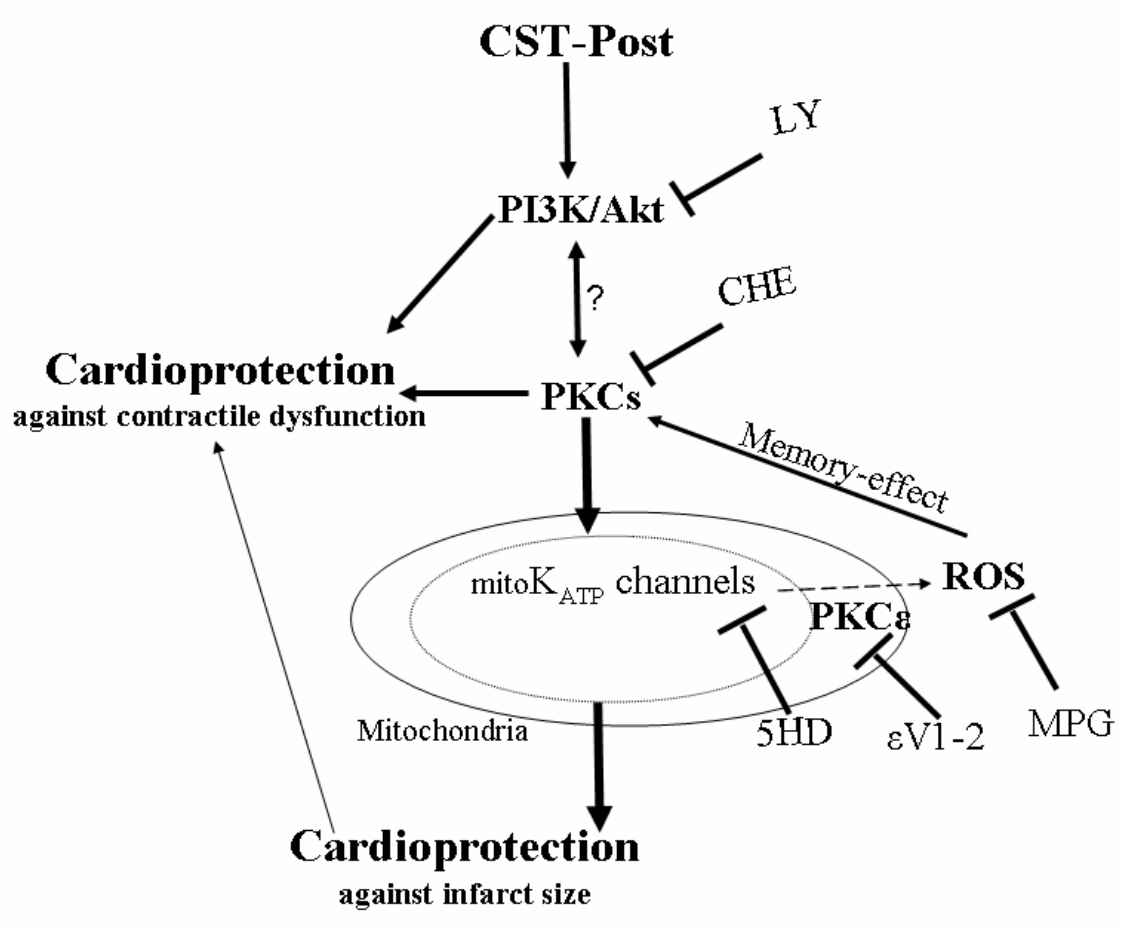

Fig.4 